\title{
THE PROBLEM OF SODIUM SALICYLATE EXCRETION IN THE BILE ${ }^{1}$
}

\author{
By BELA HALPERT, MILTON T. HANKE AND GEORGE M. CURTIS
}

(From the Department of Pathology and the Department of Surgery, University of Chicago, Chicago)

(Received for publication May 23, 1930)

In the course of studies on the excretion of various chemicals by the liver, it was discovered that sodium salicylate, and the sodium salt of diiodosalicylic acid did not appear in the bile of the rabbit, in determinable quantities, after intravenous administration of $4 \mathrm{cc}$. of a one per cent solution per kilogram of body weight (1). In view of the differences of opinion regarding the action of sodium salicylate on the biliary system as a cholagogue and as a bactericide (2), it seemed desirable to investigate the excretion of this compound by the human subject. The following is a brief record of experiments on three patients: two of these were cholecystectomized, and subsequently drained bile through their common hepatic duct; while one drained bile through a cholecystostomy.

\section{METHOD}

All three patients received by mouth a single dose of $20 \mathrm{mgm}$. of sodium salicylate per kilogram of body weight. Samples of bile and urine were obtained before administration of the compound, and subsequently the bile and urine were collected at specified intervals for a period of 12,40 and 64 hours respectively. The following method was employed to determine the presence of sodium salicylate:

Treat $10 \mathrm{cc}$. bile (or urine) with $90 \mathrm{cc}$. saturated sodium bicarbonate solution. Extract the alkaline solution with $200 \mathrm{cc}$. redistilled ethyl ether three times. Discard the ether extract. Neutralize the alkaline solution with $7 \mathrm{~N}$ sulphuric acid, using congo red paper as an indicator,

${ }^{1}$ This work has been conducted under the joint auspices of the Otho S. A. Sprague Memorial Institute and the Douglas Smith Foundation for Medical Research. 
and add 2 cc. of sulphuric acid in excess. Extract the free salicylic acid three times with ethyl ether, using $200 \mathrm{cc}$. for each extraction. Test the aqueous extract for the presence of phenols with a drop of ferric chloride. Remove the ether by passing dry air over the dish. Add 1 to $1.5 \mathrm{cc}$. of saturated sodium bicarbonate solution to the residue and wash quantitatively into a $25 \mathrm{cc}$. glass stoppered graduated cylinder. Dilute to $20 \mathrm{cc}$. with distilled water. The salicylic acid is determined in $10 \mathrm{cc}$. of this liquid by the Millon reaction as modified by Folin and Ciocalteu (3). The color is compared with that produced by $5 \mathrm{mgm}$. of salicylic acid in $10 \mathrm{cc}$. of a solution of equivalent alkalinity to the test solution.

\section{CLINICAL OBSERVATIONS}

1. E. P., a housewife of 66 , was operated on December 3, 1929, to relieve an obstructive jaundice due to stones in the common bile duct. Choledochotomy and cholecystectomy were performed, and a catheter left in place, draining the common hepatic duct. The gallbladder showed gross and microscopic evidence of a chronic cholecystitis. Three mixed gallstones (from 0.5 to $1 \mathrm{~cm}$. in diameter), composed mainly of cholesterol and calcium bilirubinate, were removed from the ductus choledochus, and four more were found in the gallbladder. The stools remained acholic until the 26th of December, 1929. Postoperative convalescence was uneventful. Our experiment began on the 8th of December, 1929. At 8 a.m. samples of bile and urine were collected and 1.2 gram of sodium salicylate was given by mouth. The bile and urine were then collected in hourly samples for 12 hours and tested for their sodium salicylate content by the method outlined above. The flow of bile averaged about $24 \mathrm{cc}$. per hour (with a minimum of 8 and a maximum of $48 \mathrm{cc}$.) and totaled $290 \mathrm{cc}$. for the 12 hours. Sodium salicylate could not be detected in any of these bile samples. The urine totaled $1381 \mathrm{cc}$. for the same period. This contained a total of 0.584 gram of salicylic acid, corresponding to 0.68 gram of sodium salicylate.

2. I. M., a housewife of 35 , was operated on October 18,1929 , to relieve symptoms due to chronic cholecystitis with cholelithiasis. The excised gallbladder showed gross and microscopic evidence of a mild chronic cholecystitis, and contained about 100 mixed gallstones (from 3 to $10 \mathrm{~mm}$. in diameter), of the facetted type, composed mainly of cholesterol and calcium carbonate. Following this operation, the patient became jaundiced and the stools acholic. At a subsequent laparotomy on October 29,1929 , the obstruction was relieved and a $\mathrm{T}$ tube was left in place in the common and hepatic ducts. The stools were still acholic when our experiment began on the 30th of November, 1929. At 8:30 p.m. samples of bile and urine were collected, and 1 gram of sodium salicylate was given by mouth. 
The bile and urine were collected for a period of 40 hours following the administration of sodium salicylate. Determinations were made on the bile obtained up to the end of the 16 th $(60 \mathrm{cc}$.) and the 40 th $(70 \mathrm{cc}$.) hours. Neither sample contained any sodium salicylate. The urine collected up to the end of the 34 th $(870 \mathrm{cc}$.) and the 40 th $(185 \mathrm{cc}$.) hours, following the administration, contained a total of 0.191 gram of salicylic acid, corresponding to 0.222 gram of sodium salicylate.

3. C. W., a housewife of 44 , underwent operation on the 17 th of December, 1929, because of symptoms and signs indicative of cholecystitis with cholelithiasis. Multiple melanotic tumor nodules greatly enlarged the liver. A cholecystostomy was performed, and the gallbladder emptied of about 150 mixed gallstones (from 2 to $8 \mathrm{~mm}$. in diameter) of the facetted type composed mainly of cholesterol, calcium carbonate and calcium bilirubinate. On the 16th of December, 1929, at 9 p.m., i.e., 15 hours before operation, 1.2 gram of sodium salicylate had been given by mouth. The quantity of bile obtained from the gallbladder at operation was insufficient for a test. The bile and urine were collected for a period of 64 hours following the operation. Determinations were made on the three samples of bile obtained at the end of the 16th $(178 \mathrm{cc}$.), 40th (60 cc.) and 64th (57 cc.) hours following the operation. Sodium salicylate could not be detected in any of these samples. The four specimens of urine obtained up to the end of the 12 th $(229 \mathrm{cc}$.), 28 th $(118 \mathrm{cc}$.), 40th $(300 \mathrm{cc}$.), and 64th (450 cc.) hours following the operation, contained a total of 0.566 gram of salicylic acid, corresponding to 0.655 gram of sodium salicylate.

\section{COMMENT}

The principal route for the elimination of sodium salicylate, according to the above observations, is the urinary tract. Sodium salicylate does not appear in the bile in recognizable amounts following oral administration of doses of $20 \mathrm{mgm}$. per kilogram of body weight. It is, therefore, reasonable to assume, that, whatever beneficial effect may follow the administration of this drug in diseases of the biliary system, is not due to the presence of salicylate in the bile.

\section{SUMMARY}

Three patients, two with drainage tubes in the common hepatic duct following cholecystectomy, and one with a cholecystostomy, were given a single dose of sodium salicylate $(20 \mathrm{mgm}$. per kilogram of body weight), and the bile and urine collected for a period of from 12 to 64 hours following the administration. The data obtained indicate that the urinary tract is the principal route of elimination, and that 
salicylate does not appear in the bile, following oral administration of a medicinal dose to patients with diseases of the biliary system. These observations are in accord with data obtained in healthy rabbits.

\section{BIBLIOGRAPHY}

1. Halpert, Béla, and Hanke, Milton T., Anat. Rec., 1929, xlii, 49. Some Observations on the Excretion of Certain Chemicals by the Biliary System of the Rabbit.

2. Hanzlik, P. J., Actions and Uses of the Salicylates and Cinchophen in Medicine. Baltimore, The Williams \& Wilkins Company, 1927.

Rolleston, Humphry, and McNee, John William, Diseases of the Liver, GallBladder and Bile-Ducts. London, Macmillan and Co., 1929, 3rd ed.

3. Folin, Otto, and Ciocalteu, Vintila, J. Biol. Chem., 1927, lxxiii, 627. On Tyrosine and Tryptophane Determinations in Proteins.

Hanke, Milton T., J. Biol. Chem., 1928, lxxix, 587. Determination of the Tyrosine Content of Proteins. 